\title{
OPTIMUM DRAFTING CONDITIONS OF POLYESTER AND VISCOSE BLEND YARNS
}

\author{
Mohammad Hatamvand $^{1,2 *}$, Seyed Abbas Mirjalili', Saeid Fattahi' ${ }^{1}$, Tariq Bashir ${ }^{2}$, Mikael Skrifvars $^{2}$ \\ ${ }^{1}$ Department of Textile Engineering, Yazd University, Yazd, Iran \\ ${ }^{2}$ Swedish Center for Resource Recovery, University of Borås, 50190 Borås, Sweden \\ ${ }^{*}$ Corresponding author e-mail: m.hatamvand@stu.yazd.ac.ir
}

\begin{abstract}
:
In this study, we used an experimental design to investigate the influence of the total draft, break draft, distance between the aprons (Clips) and production roller pressure on yarn quality in order to obtain optimum drafting conditions for polyester and viscose (PES/CV) blend yarns in ring spinning frame. We used PES fibers (1.4 dtex $\times$ $38 \mathrm{~mm}$ long) and CV fibers (1.6 dtex $\times 38 \mathrm{~mm}$ long) to spin a 20 Tex blend yarn of PES (70\%)/CV (30\%) blend ratio. When the break draft, adjustment of distance between of aprons and roller pressure is not reasonable, controlling and leading of the fibers is not sufficient for proper orientation of the fibers in the yarn structure to produce a high quality yarn. Experimental results and statistical analysis show that the best yarn quality will be obtained under drafting conditions total draft of 38, 1.2 break draft, $2.8 \mathrm{~mm}$ distance between of aprons and maximum pressure of the production top roller (18daN).
\end{abstract}

\section{Keywords:}

optimum conditions, total draft, break draft, ring spinning, yarn quality

\section{Introduction}

The ring spinning machine was invented in 1828 and it has been developed frequently. In spite of advent of modern spinning systems and their advantages, the ring spinning system is pioneer among spinning systems, because of its capability for spinning of any material to any required fineness, produce of a yarn with high structural properties, simplicity of operation and flexibility for spinning any blend ratio from various fibers [1]. Therefore, the ring spinning machine is considerable for researchers in the field of spinning for enhancing of yarn quality. In the ring spinning, drafting is roller drafting. For spinning the yarn with high quality, the draft has to be applied on the roving under the certain conditions. These conditions determine the yarn quality.

In 1945 Grishin developed a theoretical equation for calculation of sectional drafts in the roller drafting system based on the total draft, break draft, back roller gauge setting and fiber length and its variations in order to produce a drafted production with high quality [2].

In 1947, Martindale set up a utensil to measure the drafting force of cotton slivers in roller drafting system [3]. Then, some of researchers used this tool and technique to choose a suitable break draft in roller drafting system to obtain a drafted production with promoted quality [4-6].

In 2000, for high quality fine denier polyester spun yarn in ring frame, Ching-luan Su et al, investigated the effect of break draft, back roller gauge and roller pressure on quality of yarn [7]. In another research in 2003, Ching-luan Su et. al, investigated the influence of the roller gauge, break draft and roving spacing on quality of Lyocell yarn from twin roving [8]. In 2004, Ching-luan Su et al, examine the influence of roller gauge and break draft on the drafting force to determine the drafting behavior of cotton roving in two system of single and two aprons in order to obtain the highest quality of yarn [9]. In continuation, in 2005, Ching-luan Su et al, studied the effect of back roller gauge, break draft and roving twist factor on the drafting force to realize the drafting behavior during roller drafting of Polypropylene (PP) roving to approach the highest yarn quality [10]. Then, in 2006, Ching-luan Su et al, examined the drafting behavior of non-circular fiber (crossshape profile polyester) to obtain the optimum drafting conditions for spinning polyester/cotton (PES/CO) blend yarn where the effect of break draft and (PES/CO) blend ratio on the drafting force were examined [11]. Drafting force to draft a sliver depends on a few factors such as fineness of the fibers, used, the friction between of the fibers, spin finishing agent and the crimp of the fibers. Thus these factors determine proper break draft [11]. Distance between the aprons in the main draft zone and the pressure of the production top roller is proportional to yarn count and the crimps of the fibers.

The purpose of this research is to achieve an optimum drafting conditions that is led to spin a yarn with the highest quality. In this study, to optimize drafting conditions, we evaluated the influence of the factors of total draft, break draft, distance between the aprons (that is not investigated in previous researches) and the pressure of production top roller on the yarn quality. Then, we obtained a combination of factors as an optimum drafting conditions of (PES/CV) blend yarn by statistical analysis and proper experimental designs in order to produce the yarn with the highest quality. 


\section{Materials and Methods}

We used PES and CV fibers to spin the 20 Tex blend yarn of PES/CV (70\%-30\%) blend ratio on a lab ring spinning frame. The steps that fibers are passed is shown in Figure 1. The specification of the fibers, the roving, the yarn and the setting of the ring frame are given in Table1.

We fed slivers of $4.16,4.94,5.59 \mathrm{~g} / \mathrm{m}$ to roving machine to produce roving counts of 640,760 and 860 tex respectively. To avoid undesirable effects on the produced rovings quality due to different orientation of fibers for different drafts in the roving machine, same total draft of 6.5 were applied.

The yarn qualitative properties were tested on an Uster Tester IV and and tensile tester Tensorapid IV. The IPI index was defined as follows: thin places (sensitivity degree: $-50 \%$ ) + thick places (sensitivity degree: $+50 \%$ ) + neps (sensitivity degree: $200 \%$ ) per $1000 \mathrm{~m}$. The number of tests per sample for the tensile test was 30 and for Uster Tester was 2(for each test was $1000 \mathrm{~m}$ length of yarn). In tensile tester, the gauge length was $50 \mathrm{~cm}$ and speed clamp was $5 \mathrm{~m} / \mathrm{min}$. All tests were carried out under similar conditions of $65 \pm 5 \% \mathrm{RH}$ and $20 \pm 2^{\circ} \mathrm{C}$.

First of all, to identify the effective factors on the yarn quality, primarily, factorial design of $2^{f}$ was applied as the experimental design. In this design, instead of many states, we have to choose a low level and high level from each factor of total draft, break draft, pressure of production top roller and distance between the aprons (Clips) according to Table 2. There are 16 $\left(2^{4}=16\right)$ states which should be evaluated if these factors are effective on the yarn quality or not [12].

Fibers blend $\longrightarrow$ Blowing and Blending $\longrightarrow$ Carding $\longrightarrow$ Draw frame $(1)$

Ring Frame $\longleftarrow$ Flyer Machine $\longleftarrow$ Draw frame (2)

Figure 1. The process flowchart of yarn production (fibers to yarn).

Table 1. Specification of material, production and ring frame setting, used.

\begin{tabular}{|c|c|}
\hline \multirow{2}{*}{ Fibers type and Blend Ratio } & Polyester (PES), $70 \%$ \\
\cline { 2 - 2 } & Viscose (CV), $30 \%$ \\
\hline \multirow{2}{*}{ Fiber fineness, dtex } & Polyester (PES), 1.4 \\
\hline \multirow{2}{*}{ Fiber length (mm) } & Viscose (CV), 1.6 \\
\hline Roving Count, (Tex) & Polyester (PES), 38 mm \\
\hline Roving Twist, (t.p.m) & Viscose (CV), 38 mm \\
\hline Yarn Count, (Tex) & $640,760,860$ \\
\hline Yarn Twist, (t.p.m) & 28 \\
\hline Back roller gauge, (mm) & 20 \\
\hline Front roller gauge, (mm) & 780 \\
\hline Spindle speed, (r.p.m) & 37 \\
\hline Traveler mass, (mgr) & 16 \\
\hline
\end{tabular}

Table 2. Factorial design of $2 \mathrm{f}$.

\begin{tabular}{|c|c|c|c|c|c|}
\hline State & Total Draft & Roving Count (Tex) & Break draft & Pressure of Top Roller, (daN) & Clips (mm) \\
\hline 1 & 43 & 860 & 1.5 & 18 & 2.8 \\
\hline 2 & 43 & 860 & 1.5 & 18 & 2.2 \\
\hline 3 & 43 & 860 & 1.5 & 10 & 2.8 \\
\hline 4 & 43 & 860 & 1.5 & 10 & 2.2 \\
\hline 5 & 43 & 860 & 1.2 & 18 & 2.8 \\
\hline 6 & 43 & 860 & 1.2 & 18 & 2.2 \\
\hline 7 & 43 & 860 & 1.2 & 10 & 2.8 \\
\hline 8 & 43 & 860 & 1.2 & 10 & 2.2 \\
\hline 9 & 32 & 640 & 1.5 & 18 & 2.8 \\
\hline 10 & 32 & 640 & 1.5 & 18 & 2.2 \\
\hline 11 & 32 & 640 & 1.5 & 10 & 2.8 \\
\hline 12 & 32 & 640 & 1.5 & 10 & 2.2 \\
\hline 13 & 32 & 640 & 1.2 & 18 & 2.8 \\
\hline 14 & 32 & 640 & 1.2 & 18 & 2.2 \\
\hline 15 & 32 & 640 & 1.2 & 10 & 2.8 \\
\hline 16 & 32 & 640 & 1.2 & 10 & 2.2 \\
\hline
\end{tabular}


We analyzed the results of factorial design of $2^{\mathrm{f}}$ experiments using statistical software, SPSS 22. After identification of effective factors, we investigated the influence of the variations of these factors on the yarn quality by statistical analysis. At next step, we set the distance between the aprons on $2.5 \mathrm{~mm}$ (Lilac Clips) and the pressure of the roller on maximum on the base of normal setting in actual spinning. Then we changed break draft from 1.1 to 1.9 and then we analyzed the data to obtain the most suitable break draft. Afterwards the break draft was set on the optimum draft and other factors were changed according to the illustrated method. Finally, optimum drafting conditions for (PES/CV) blend yarns in the ring spinning frame obtained using statistical analysis.

\section{Results and Discussion}

Table 3 illustrates analyses of factorial design of $2^{f}$ experiments. Column Sig. in table 3 depicts significant of the influence of factors on quality parameters of yarn. If a factor is effective on the quality parameters of yarn in level of $5 \%$, its Sig. is less than 0.05 . Results and statistical analysis reveal that four factors of total draft, break draft, the pressure of the production top roller and the distance between the aprons are effective on the quality parameters of the yarn according to table 3 . At next step, for more precise investigation, we limited the factors to three factors including the break draft, the pressure of the production top roller and the distance between the aprons. Therefore, on the base of normal setting in actual spinning, we set the total draft on 38 with roving of 760 tex and we carried out another steps according to illustrated recipe as mentioned in Methods.

According to Table 4, results and statistical analysis show that the variation of break draft is effective on CV\% and Elongation of the yarn in the level of $7 \%$, on Tenacity of yarn in the level of $5 \%$.

Figure 2 shows the relationship between the break draft and CV\% of yarn. Break draft was applied on roving to overcome on static friction of roving. When the break draft is low, drafting force cannot overcome on inter-fibers friction, resulting in thin and thick places in the yarn. When the break draft is too high, because of the lack of any apron and leader in break draft zone, a drafting wave in the yarn would occur and CV\% of the yarn would be observed. Therefore inappropriate break draft leads to critical draft and yarn mass irregularity. Suitable break draft depends on the fibers fineness, fibers cross sectional shapes, friction between fibers and linear density of the roving. Optimum draft takes place in 1.2 and resulting in higher Tenacity and Elongation of the yarn, shown in Figure 3 . Thus according to the results, break draft of 1.2 was selected as optimum break draft.

Table 3. Analyses of Factorial design of $2^{f}$ experiments.

\begin{tabular}{|c|c|c|c|c|c|c|}
\hline Quality Factor & Dependent Variable & Type III Sum of Squares & df & Mean Square & $\mathbf{F}$ & Sig. \\
\hline \multirow{5}{*}{ Total Draft } & CV\% & 4.379 & 1 & 4.379 & 29.045 & 0.000 \\
\hline & IPI & 33420.410 & 1 & 33420.410 & 20.252 & 0.001 \\
\hline & Hairiness & 0.092 & 1 & 0.092 & 50.534 & 0.000 \\
\hline & Tenacity & 10.288 & 1 & 10.288 & 9.858 & 0.009 \\
\hline & Elongation & 2.714 & 1 & 2.714 & 7.801 & 0.017 \\
\hline \multirow{5}{*}{ Break draft } & CV\% & 2.814 & 1 & 2.814 & 18.666 & 0.001 \\
\hline & IPI & 5301.660 & 1 & 5301.660 & 3.213 & 0.101 \\
\hline & Hairiness & $6.250^{\wedge}-6$ & 1 & $6.250^{\wedge}-6$ & 0.003 & 0.954 \\
\hline & Tenacity & 1.340 & 1 & 1.340 & 1.284 & 0.281 \\
\hline & Elongation & 0.466 & 1 & 0.466 & 1.339 & 0.272 \\
\hline \multirow{5}{*}{$\begin{array}{l}\text { Pressure of top } \\
\text { roller }\end{array}$} & CV\% & 1.556 & 1 & 1.556 & 10.323 & 0.008 \\
\hline & IPI & 10314.941 & 1 & 10314.941 & 6.251 & 0.030 \\
\hline & Hairiness & 0.000 & 1 & 0.000 & 0.169 & 0.689 \\
\hline & Tenacity & 3.563 & 1 & 3.563 & 3.414 & 0.092 \\
\hline & Elongation & 1.363 & 1 & 1.363 & 3.918 & 0.073 \\
\hline \multirow{5}{*}{ Clips } & CV\% & 0.761 & 1 & 0.761 & 5.050 & 0.046 \\
\hline & IPI & 8847.754 & 1 & 8847.754 & 5.361 & 0.041 \\
\hline & Hairiness & 0.006 & 1 & 0.006 & 3.317 & 0.096 \\
\hline & Tenacity & 0.381 & 1 & 0.381 & 0.365 & 0.558 \\
\hline & Elongation & 8.108 & 1 & 8.108 & 23.304 & 0.001 \\
\hline
\end{tabular}


Table 4. Table of ANOVA test of break draft.

\begin{tabular}{|c|c|c|c|c|c|c|}
\hline \multicolumn{2}{|c|}{ Quality Factor } & $\begin{array}{l}\text { Sum of } \\
\text { Squares }\end{array}$ & df & Mean Square & $\mathbf{F}$ & Sig. \\
\hline \multirow{3}{*}{ CV\% } & Between Groups & 4.130 & 8 & 0.516 & 2.951 & 0.064 \\
\hline & Within Groups & 1.574 & 9 & 0.175 & & \\
\hline & Total & 5.704 & 17 & & & \\
\hline Elongation & $\begin{array}{c}\text { Between Groups } \\
\text { Within Groups } \\
\text { Total }\end{array}$ & $\begin{array}{c}22.303 \\
244.974 \\
267.276\end{array}$ & $\begin{array}{c}8 \\
171 \\
179\end{array}$ & $\begin{array}{l}2.788 \\
1.433\end{array}$ & 1.946 & 0.056 \\
\hline Tenacity & $\begin{array}{c}\text { Between Groups } \\
\text { Within Groups } \\
\text { Total }\end{array}$ & $\begin{array}{c}91.850 \\
861.439 \\
953.289\end{array}$ & $\begin{array}{c}8 \\
171 \\
179\end{array}$ & $\begin{array}{c}11.481 \\
5.038\end{array}$ & 2.279 & 0.024 \\
\hline
\end{tabular}

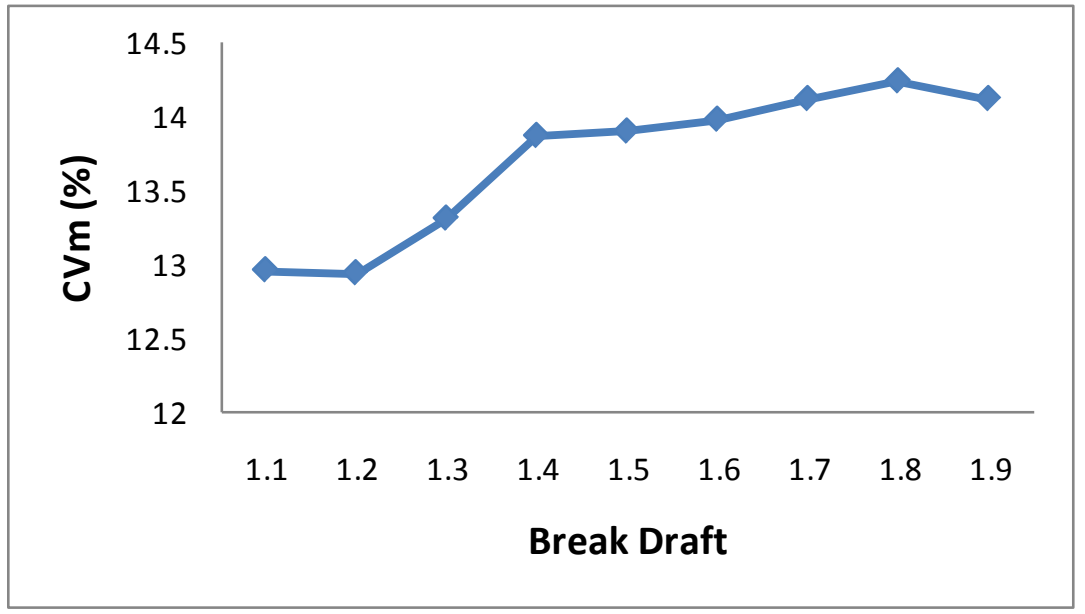

Figure 2. Relationship between break draft and $\mathrm{CV} \%$ of the yarn.

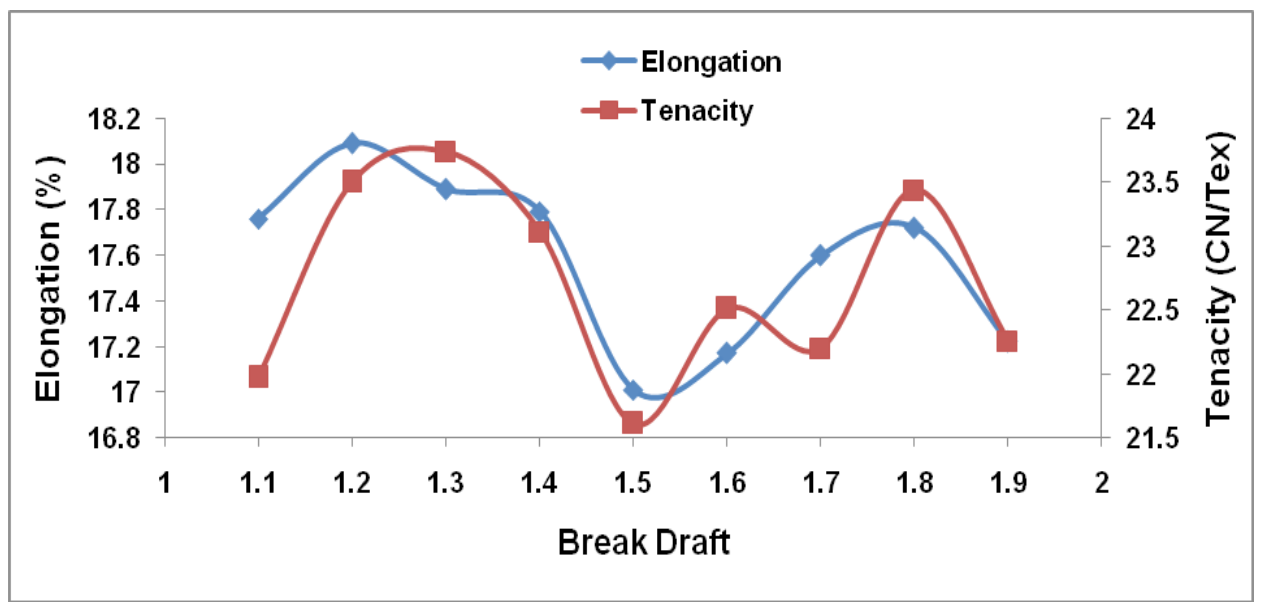

Figure 3. Relationship between break draft with Elongation(\%) and Tenacity (CN/Tex) of yarn.

In subsequent stage, we set the break draft on 1.2, the pressure of the production top roller on the maximum (18 daN) and investigated the effect of the distance between two aprons on the yarn quality. The distance between two aprons in main draft zone will be adjusted by the clips. This distance was changed in 6 states: 1. Red clips (2mm), 2. Yellow clips $(2.2 \mathrm{~mm})$, 3.Lilac clips $(2.5 \mathrm{~mm}), 4$. White clips $(2.8 \mathrm{~mm}), 5$. Gray clips $(3.3 \mathrm{~mm})$ and 6 . Black clips $(3.8 \mathrm{~mm})$. Table 5 shows that the distance between two aprons influences on the elongation and tenacity of the yarn. This distance will be adjusted according to yarn count and crimp of the fibers. If the distance is small, the fibers cannot move easily and if the distance is large, there is not adequate control to lead the fibers towards production roller, which results in disorder of the fibers in the yarn structure and reduce the quality parameters. Figure 4 shows that optimum distance between aprons takes places in White clips $(2.8 \mathrm{~mm})$. Therefore, in the last step, the total draft was set on 38 , the break draft on 1.2, the distance between two aprons on $2.8 \mathrm{~mm}$ (white clips) and the effect of the pressure of production top roller on yarn quality was investigated. 


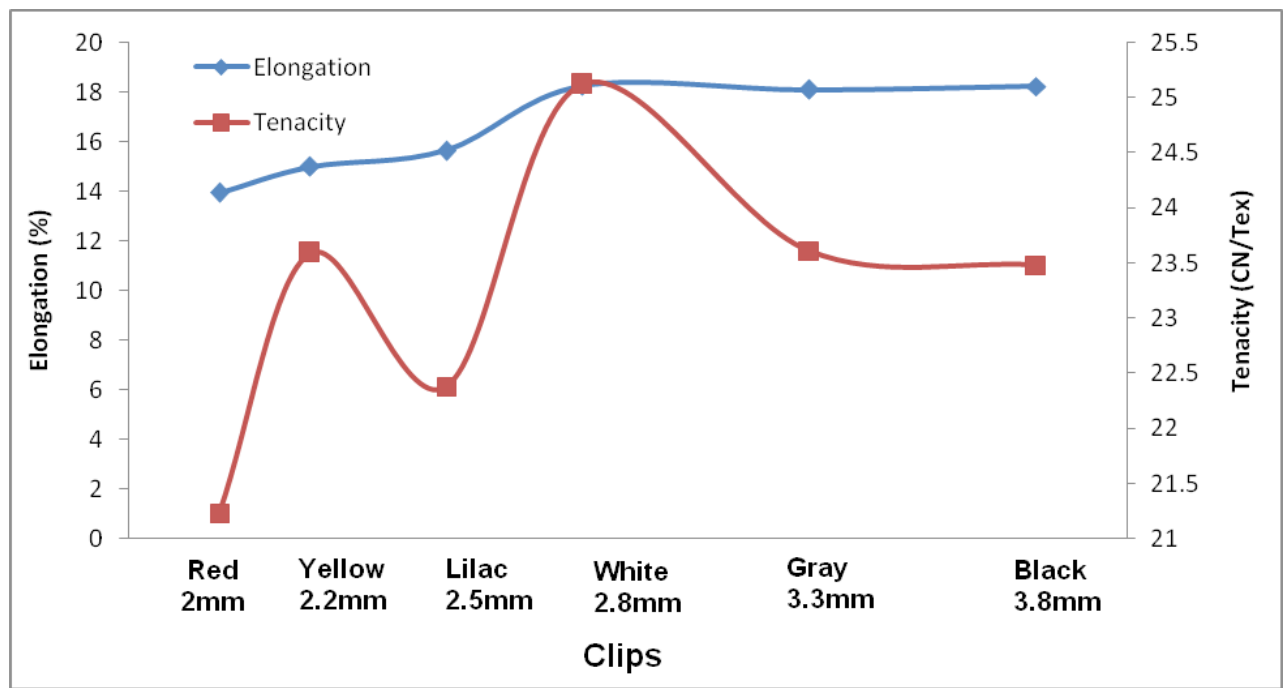

Figure 4. Relationship between Spacer with Elongation (\%) and Tenacity (CN/Tex) of yarn.

Table 5. Table of Anova test of distance between two aprons.

\begin{tabular}{|c|c|c|c|c|c|c|}
\hline \multicolumn{2}{|c|}{ Quality Factor } & $\begin{array}{c}\text { Sum of } \\
\text { Squares }\end{array}$ & df & Mean Square & F & Sig. \\
\hline \multirow{3}{*}{ Elongation } & Between Groups & 365.479 & 5 & 73.096 & 49.787 \\
& Within Groups & 167.372 & 114 & 1.468 & $\mathbf{0 . 0 0 0}$ \\
& Total & 532.851 & 119 & 5 & 34.615 & 10.155 \\
Tenacity & Between Groups & 173.073 & 114 & 3.409 & $\mathbf{0 . 0 0 0}$ \\
& Within Groups & 388.580 & 119 & & \\
\hline
\end{tabular}

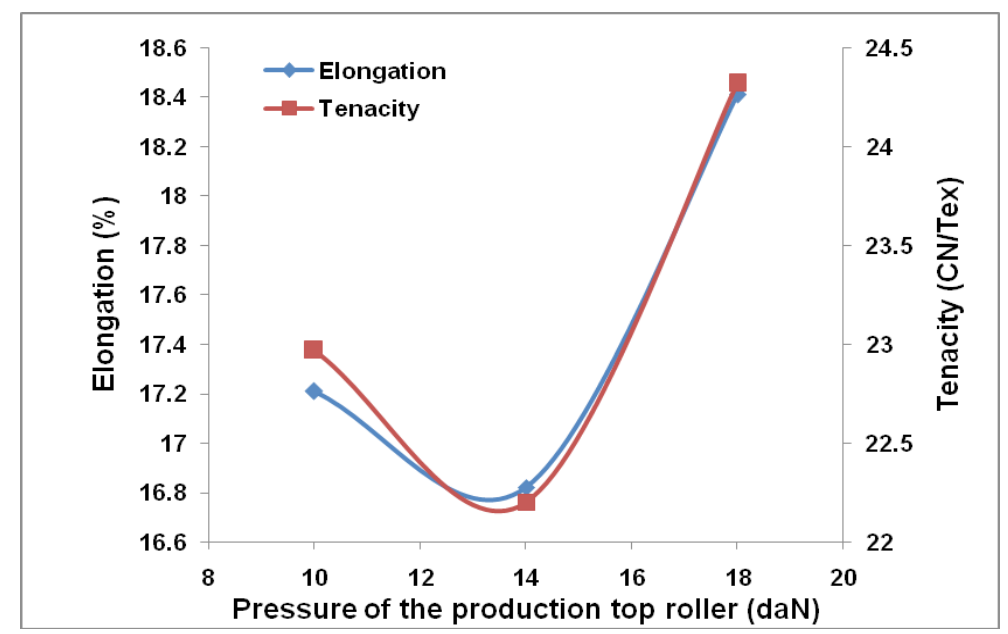

Figure 5. Relationship between pressure of the production top roller with Elongation and (\%)Tenacity (CN/Tex) of the yarn.

To study the effect of the pressure of production top roller on the yarn quality, we set break draft and distance between aprons according to previous optimum results and the pressure was altered in three pressures: 1. High pressure (18 daN), 2. Medium pressure (14 daN) and 3. Low pressure (10 daN). Statistical analyses in table 6 indicate that the pressure of production top roller is effective on the elongation and the tenacity of the yarn in significant level of $5 \%$. The pressure of production top roller depends on the number of fibers and softness of top roller. When the pressure is low, catching the fibers will be weak and resulting in escaping the fibers and no orientation in suitable structural direction in yarn and decline of yarn quality. Optimum pressure of top roller is in maximum pressure (18 daN). Figure 5 conforms this fact.

\section{CONCLUSIONS}

On basis of the obtained results from this work, we found out for $(\mathrm{PES} / \mathrm{CV})$ blend yarns in the ring spinning frame for PES (1.4 dtex $\times 38 \mathrm{~mm}$ long) and CV fibers (1.6 dtex $\times 38 \mathrm{~mm}$ long) to spin a 20 Tex blend yarn of PES $(70 \%) / C V(30 \%)$ blend ratio: 
Table 6. Table of ANOVA test of pressure of the production top roller.

\begin{tabular}{|c|c|c|c|c|c|c|}
\hline \multicolumn{2}{|c|}{ Quality Factor } & $\begin{array}{l}\text { Sum of } \\
\text { Squares }\end{array}$ & df & Mean Square & $\mathbf{F}$ & Sig. \\
\hline Elongation & $\begin{array}{c}\text { Between Groups } \\
\text { Within Groups } \\
\text { Total }\end{array}$ & $\begin{array}{c}27.425 \\
110.204 \\
137.629 \\
\end{array}$ & $\begin{array}{c}2 \\
57 \\
59\end{array}$ & $\begin{array}{c}13.713 \\
1.933\end{array}$ & 7.092 & 0.002 \\
\hline Tenacity & $\begin{array}{c}\text { Between Groups } \\
\text { Within Groups } \\
\text { Total }\end{array}$ & $\begin{array}{c}46.328 \\
317.545 \\
363.874 \\
\end{array}$ & $\begin{array}{c}2 \\
57 \\
59\end{array}$ & $\begin{array}{c}23.164 \\
5.571\end{array}$ & 4.158 & 0.021 \\
\hline
\end{tabular}

1. The total draft influences on the all of yarn qualitative properties such that with increasing total draft the qualitative properties of the yarn will decline.

2. The break draft is effective on the $\mathrm{CV} \%$, tenacity and elongation of the yarn. In comparison with other research works, fibers showed similar behavior against break draft.

3. The distance between aprons in the main draft zone is effective on the tenacity and elongation of the yarn.

4. The pressure of the production top roller is effective on the tenacity and elongation of the yarn.

According to this research work the best quality of the yarn for illustrated materials would obtain under drafting conditions of 38 total drafts, 1.2 break draft, $2.8 \mathrm{~mm}$ distance between of the aprons (white clips) and maximum pressure of the top roller (18 daN).

In a spinning mill, in order to promotion of yarn quality in ring frame, before manufacture of yarn in high volume of production, obtaining the optimum drafting conditions is vital. It seems we will be able to obtain optimum drafting conditions for different fibers to spin yarn in ring frame using suitable experimental design and statistical analysis.

\section{ACKNOWLEDGEMENTS}

Authors would like to appreciate Bahar Ris Spinning Co. for their facilities and technical support during this research work.

\section{References}

[1] Klein, W. (1987). Short Staple Spinning Series (Manual of Textile Technology), Vole 4, A Practical Guide to Ring Spinning, The Textile Institute, UK (Manchester).

[2] Grishin P.F. (1945). A Theory of Drafting and Its Practical Application. Journal of Textile Institute, 45, 167-267.

[3] Martindale, J.G. (1947). An instrument for measurement of the forces operating between fibers during drafting. Journal of Textile Institute, 38, 151-166.

[4] Roder, H. L. (1958). The Evaluation of the Spinning Properties of Man-made Staple fibers. Textile Research Journal, 28, 819-839.

[5] Audivert, R. (1974). The Relation between the Drafting Force, Draft, and Setting in the roller-drafting of staple-fiber slivers. Journal of Textile Institute, 65, 325-327.

[6] Su, C.I., Lo, K.J and Lee, J.Y. (1998). Drafting Force of FineDenier Polyester Fibers. Textile Research Journal, 68(8), 559-563.

[7] Su, C.I. and Lo, K.J. (2000). Optimum Drafting Conditions of Fine- Denier Polyester Spun Yarn. Textile Research Journal, 70(2), 93-97.

[8] Su, C.I., Liu, C.H and Jiang, J.Y. (2003). Drafting Force of Twin Spun yarn, Textile Research Journal, 73(9), 815-818.

[9] Su, C.I. and Jiang, J.Y. (2004). Fine Count Yarn Spun with a High Draft Ratio, Textile Research Journal, 74(2), 123-126.

[10] Su, C.I. and Lai, W.C. (2005). Optimum Drafting Conditions of Polypropylene Spun Yarns, Textile Research Journal, 75(1), 6-8.

[11] Su, C.I. and Fang, J.X. (2006). Optimum Drafting Conditions of Non-Circular Polyester and Cotton Blend Yarns, Textile Research Journal, 76(6), 441-447.

[12] Leaf, G. A. V. (1984). Practical Statistics for the Textile Industry, The Textile Institute, UK (Manchester). 